\title{
BMJ Open Diagnostic values of soluble mesothelin-related peptides for malignant pleural mesothelioma: updated meta-analysis
}

\author{
Ai Cui, ${ }^{1}$ Xiao-Guang Jin, ${ }^{1}$ Kan Zhai, ${ }^{2}$ Zhao-Hui Tong, ${ }^{1}$ Huan-Zhong Shi ${ }^{1,2}$
}

To cite: Cui $A$, Jin $X-G$, Zhai $\mathrm{K}$, et al. Diagnostic values of soluble mesothelinrelated peptides for malignant pleural mesothelioma: updated meta-analysis. BMJ Open 2014;4:e004145. doi:10.1136/bmjopen-2013004145

- Prepublication history and additional material for this paper is available online. To view these files please visit the journal online (http://dx.doi.org/10.1136/ bmjopen-2013-004145).

AC and X-GJ contributed equally.

Received 29 September 2013 Revised 16 January 2014 Accepted 21 January 2014

CrossMark

\section{${ }^{1}$ Department of Respiratory and Critical Care Medicine, Beijing Chaoyang Hospital, Capital Medical University, Beijing, China \\ ${ }^{2}$ Center of Medical Research, Beijing Institute of Respiratory Diseases, Beijing, China}

Correspondence to Dr Huan-Zhong Shi; shihuanzhong@sina.com

\section{ABSTRACT}

Objective: Although the values of soluble mesothelinrelated peptides (SMRPs), including mesothelin and megakaryocyte potentiating factor, in serum and/or pleural fluid for diagnosing malignant pleural mesothelioma (MPM) have been extensively studied, the exact diagnostic accuracy of these SMRPs remains controversial. The purpose of the present meta-analysis is to update the overall diagnostic accuracy of SMRPs in serum and, furthermore, to establish diagnostic accuracy of SMRPs in pleural fluid for MPM.

Design: Systematic review and meta-analysis. Methods: A total of 30 articles of diagnostic studies were included in the current meta-analysis. Sensitivity, specificity and other measures of accuracy of SMRPs in serum and pleural fluid for the diagnosis of MPM were pooled using random effects models. Summary receiver operating characteristic curves were used to summarise overall test performance.

Results: The summary estimates of sensitivity, specificity, positive likelihood ratio, negative likelihood ratio and diagnostic $\mathrm{OR}$ were $0.61,0.87,5.71,0.43$ and 14.43 , respectively, for serum and $0.79,0.85$, $4.78,0.30$ and 19.50 , respectively, for pleural fluid. It was also found that megakaryocyte potentiating factor in serum had a superior diagnostic accuracy compared with mesothelin for MPM.

Conclusions: SMRPs in both serum and pleural fluid are helpful markers for diagnosing MPM with similar diagnostic accuracy. The negative results of SMRP determinations are not sufficient to exclude non-MPM, and the positive test results indicate that further invasive diagnostic steps might be necessary for the diagnosis of MPM.

\section{INTRODUCTION}

Malignant pleural mesothelioma (MPM) is a highly aggressive almost uniformly fatal tumour primarily caused by exposure to asbestos. ${ }^{1}$ Current therapeutic options for MPM are limited and the prognosis is poor. ${ }^{2}$ When patients are treated with standard of care chemotherapy, cisplatin and an antifolate, median survival is approximately

\section{Strengths and limitations of this study}

- The studies included in this meta-analysis were methodologically satisfactory and their results were consistent and close.

- The subjects in the control groups were very heterogeneous from one study to another.

- Various cut-off points were used for distinguishing between malignant pleural mesothelioma and the other diseases.

- Conference abstracts, letters to the editors, and non-English language studies were excluded.

- Pathological types of malignant pleural mesothelioma were not specified in some studies.

1 year. ${ }^{3}{ }^{4}$ Early diagnosis offers the best hope for a favourable prognosis; however, the early and reliable diagnosis of MPM is extremely difficult as only $5 \%$ of patients present with stage IA disease. ${ }^{5}{ }^{6}$ There is therefore a critical need for reliable and non-invasive tools that shorten this diagnostic delay.

Many soluble markers, such as mesothelin family proteins, in serum or pleural fluid (PF) have been evaluated to facilitate the noninvasive diagnostic investigation for $\mathrm{MPM}^{6}$ Mesothelin is a $40 \mathrm{kDa}$ cell surface glycoprotein that is highly expressed in MPM, pancreatic cancers, ovarian cancers and some other cancers. It is synthesised as a precursor $69 \mathrm{kDa}$ protein and forms two proteins, the membrane-bound mesothelin and a soluble $31 \mathrm{kD}$ N-terminal fraction, megakaryocyte potentiating factor (MPF), also denominated 'N-ERC/mesothelin'. 7 Although mesothelin is bound to the cell membrane, a circulating form termed 'soluble mesothelin' has been reported to be related to abnormal splicing events leading to synthesis of a secreted protein and to an enzymatic cleavage from membrane-bound mesothelin. ${ }^{8}$

It has been well documented that soluble mesothelin-related peptides (SMRPs), including 
both soluble mesothelin and MPF, have been found in human serum and $\mathrm{PF}^{9}{ }^{10}$ The diagnostic accuracy of SMRP detections for MPM has been extensively studied, but the exact role of these detections needs to be elucidated. In 2010 we performed and published a first meta-analysis reporting the overall diagnostic accuracy of serum SMRPs for diagnosing MPM, and our results showed that serum SMRP determinations could play a role in the diagnosis of MPM. ${ }^{11}$ More recently, Hollevoet et $a l^{12}$ performed an individual patient data meta-analysis to evaluate serum SMRP levels for diagnosing MPM, and found that a positive test result at a high specificity threshold is a strong incentive to urge further diagnostic steps; however, the poor sensitivity of SMRPs limits its added value to early diagnosis of MPM. Since that time, many additional clinical studies determining the concentrations of SMRPs in serum and PF have been reported. We therefore performed the present meta-analysis to update the overall diagnostic accuracy of serum SMRPs and, furthermore, to establish the accuracy of PF SMRPs for diagnosing MPM.

\section{METHODS}

Search strategy and study selection

MEDLINE (PubMed database) and EMBASE were searched for suitable studies up to 28 November 2013; no early date limit was applied. Search keywords included 'soluble mesothelin-related peptides/SMRP', 'mesothelin', 'megakaryocyte potentiating factor/MPF' and 'mesothelioma'. Articles were also identified by use of the related articles function in PubMed. References of articles identified were further searched manually. Although no language restrictions were imposed initially, for the full-text review and final analysis our resources only permitted review of English articles. Conference abstracts and letters to journal editors were excluded because of the limited data presented in them.

A study was included in the meta-analysis when it provided SMRP values in serum and/or PF for both sensitivity and specificity of the diagnosis of MPM. Studies including at least 10 specimens were selected to be included in the meta-analysis, since very small studies may be vulnerable to selection bias. Publications with evidence of possible overlap of patients with other studies were discussed by AC, X-GJ and $\mathrm{KZ}$ and only the best quality study was used. Two reviewers (Z-HT and H-ZS) independently judged study eligibility while screening the citations. Disagreements were resolved by consensus.

\section{Data extraction and quality assessment}

The final set of English articles was assessed independently by two reviewers (AC and X-GJ). Data retrieved from the reports included author, publication year, study characteristics, participant characteristics, diagnostic methods, sensitivity and specificity data, cut-off value and methodological quality. All eligible studies were assessed for methodological quality using guidelines published by the Standards for Reporting Diagnostic Accuracy (STARD, maximum score 25) initiative $^{13}$ (ie, guidelines that aim to improve the quality of reporting in diagnostic studies) and the Quality Assessment for Studies of Diagnostic Accuracy (QUADAS, maximum score 14) tool $^{14}$ (ie, appraisal by use of empirical evidence, expert opinion and formal consensus to assess the quality of primary studies of diagnostic accuracy).

\section{Statistical analyses}

Standard methods recommended for meta-analyses of diagnostic test evaluations were used. ${ }^{15}$ Analyses were performed using two statistical software programs (Stata V.9; Stata Corporation; College Station, Texas, USA; and Meta-DiSc for Windows; XI Cochrane Colloquium; Barcelona, Spain). We computed the following measures of test accuracy for each study: sensitivity, specificity, positive likelihood ratio (PLR), negative likelihood ratio (NLR) and diagnostic OR (DOR).

The analyses were based on summary receiver operating characteristic (SROC) curves. ${ }^{15} 16$ The sensitivity and specificity for the single test threshold identified for each study were used to plot an SROC curve. ${ }^{16}{ }^{17}$ A random effects model was used to calculate the average sensitivity, specificity and other measures across studies $^{18} 19$ and $\chi^{2}$ and Fisher exact tests were used to detect statistically significant heterogeneity. Since publication bias is of concern for meta-analyses of diagnostic studies, we tested for the potential presence of this bias using funnel plots and the Egger test. ${ }^{20}$

\section{RESULTS}

\section{Studies included}

After independent review, 62 publications determining concentrations of human SMRPs in serum and/or PF were considered to be eligible for inclusion in the meta-analysis. Of these publications, 32 were excluded (see online supplementary appendix 1), leaving 30 publications available for analysis of diagnostic accuracy of SMRPs. ${ }^{21-50}$ Eleven publications from 12 studies ${ }^{21-31}$ were included in our previous meta-analysis ${ }^{11}$ and an additional 19 publications from 28 studies $^{32-50}$ were added in the current meta-analysis.

Multiple ELISA kits were available for determining SMRP concentrations. Mesomark, which has been approved by the US Food and Drug Administration, was used to determine mesothelin in most studies and other mesothelin ELISA kits were used in the other four studies. ${ }^{21} 303134$ Serum mesothelin concentrations were determined in 23 studies (22 articles) $)^{21} \quad 23-3133 \quad 3537-40424446474950$ and serum MPF concentrations were determined in five studies $^{22} 30323746$ (table 1). In the study by Scherpereel et $a l^{23}$ the authors compared serum SMRP concentrations in patients with MPM with those in patients exposed to 
Table 1 Study summary of SMRPs in serum

\begin{tabular}{|c|c|c|c|c|c|c|c|c|c|}
\hline \multirow[b]{2}{*}{ Study } & \multirow[b]{2}{*}{ Subjects, n } & \multirow[b]{2}{*}{ SMRPS } & \multirow[b]{2}{*}{ Cut-off } & \multicolumn{4}{|c|}{ Test results } & \multicolumn{2}{|c|}{ Quality scores } \\
\hline & & & & $\overline{T P}$ & FP & FN & TN & STARD & QUADAS \\
\hline Robinson et $a^{21}$ & 272 & Mesothelin & 0.218 OD & 37 & 10 & 7 & 218 & 16 & 11 \\
\hline Scherpereel et $a^{P^{3}}$ & 83 & Mesothelin & $0.93 \mathrm{nmol} / \mathrm{L}$ & 48 & 4 & 12 & 19 & 14 & 10 \\
\hline Scherpereel et $a^{p^{3}}$ & 90 & Mesothelin & $1.85 \mathrm{nmol} / \mathrm{L}$ & 35 & 8 & 25 & 22 & 14 & 10 \\
\hline Beyer et $a f^{4}$ & 1086 & Mesothelin & $1.5 \mathrm{nmol} / \mathrm{L}$ & 46 & 66 & 42 & 932 & 16 & 12 \\
\hline Di Serio et $a^{p^{7}}$ & 116 & Mesothelin & $1.5 \mathrm{nmol} / \mathrm{L}$ & 16 & 7 & 8 & 85 & 14 & 12 \\
\hline Amati et $a f^{8}$ & 170 & Mesothelin & $1.9 \mathrm{nmol} / \mathrm{L}$ & 16 & 15 & 6 & 133 & 12 & 9 \\
\hline Shiomi et $a^{29}$ & 293 & MPF & $5.6 \mathrm{ng} / \mathrm{mL}$ & 28 & 17 & 11 & 237 & 20 & 13 \\
\hline Iwahori et $a \beta^{\beta 0}$ & 156 & MPF & $19.1 \mathrm{ng} / \mathrm{mL}$ & 20 & 14 & 7 & 115 & 14 & 11 \\
\hline Iwahori et $a^{30}$ & 156 & Mesothelin & $123.7 \mathrm{ng} / \mathrm{mL}$ & 11 & 8 & 16 & 121 & 14 & 11 \\
\hline Hollevoet et $a^{\beta 7}$ & 507 & Mesothelin & $1.89 \mathrm{nmol} / \mathrm{L}$ & 56 & 25 & 29 & 397 & 20 & 11 \\
\hline Hollevoet et $a \beta^{37}$ & 507 & MPF & $13.46 \mathrm{ng} / \mathrm{mL}$ & 58 & 13 & 27 & 409 & 20 & 11 \\
\hline Creaney et $a \beta^{\beta 8}$ & 155 & Mesothelin & $1.6 \mathrm{nmol} / \mathrm{L}$ & 44 & 4 & 22 & 85 & 13 & 11 \\
\hline Cristaudo et $a^{\beta 9}$ & 235 & Mesothelin & $1.0 \mathrm{nmol} / \mathrm{L}$ & 19 & 41 & 12 & 163 & 16 & 10 \\
\hline Dipalma et $a{ }^{40}$ & 354 & Mesothelin & $1.2 \mathrm{nmol} / \mathrm{L}$ & 22 & 66 & 14 & 252 & 15 & 10 \\
\hline Ashour et a/ ${ }^{42}$ & 123 & Mesothelin & $0.55 \mathrm{nmol} / \mathrm{L}$ & 30 & 34 & 8 & 51 & 13 & 9 \\
\hline Amany et $a{ }^{44}$ & 40 & Mesothelin & $3.3 \mathrm{nmol} / \mathrm{L}$ & 19 & 1 & 1 & 19 & 12 & 9 \\
\hline Creaney et al ${ }^{46}$ & 121 & Mesothelin & $2.4 \mathrm{nmol} / \mathrm{L}$ & 40 & 3 & 26 & 52 & 13 & 11 \\
\hline Creaney et al ${ }^{46}$ & 121 & MPF & $33.2 \mathrm{ng} / \mathrm{mL}$ & 34 & 3 & 32 & 52 & 13 & 11 \\
\hline Ferro et $a f^{47}$ & 102 & Mesothelin & $1.08 \mathrm{nmol} / \mathrm{L}$ & 20 & 9 & 23 & 50 & 14 & 9 \\
\hline Hooper et $\left.a\right|^{49}$ & 203 & Mesothelin & $1.5 \mathrm{nmol} / \mathrm{L}$ & 16 & 62 & 11 & 114 & 15 & 12 \\
\hline
\end{tabular}

asbestos with benign pleural lesions and in patients with pleural metastasis of carcinomas separately using two different cut-off values; we therefore treated these research data as two independent studies. SMRP concentrations in PF were determined in 11 articles from 12 studies (mesothelin in 11 and MPF in 1) (table 2). ${ }^{23} 343641-4749$

The clinical characteristics of the studies along with the STARD and QUADAS scores are shown in tables 1 and 2.

Table 2 Study summary of SMRPs in pleural fluids

\begin{tabular}{|c|c|c|c|c|c|c|c|c|c|}
\hline \multirow[b]{2}{*}{ Study } & \multirow[b]{2}{*}{ Patients, n } & \multirow[b]{2}{*}{ SMRPS } & \multirow[b]{2}{*}{ Cut-off } & \multicolumn{4}{|c|}{ Test results } & \multicolumn{2}{|c|}{ Quality scores } \\
\hline & & & & $\overline{T P}$ & FP & FN & $\overline{T N}$ & $\overline{\text { STARD }}$ & QUADAS \\
\hline Scherperel et $a^{23}$ & 92 & Mesothelin & $10.4 \mathrm{nmol} / \mathrm{L}$ & 33 & 15 & 10 & 34 & 14 & 10 \\
\hline Davies et $a \beta^{34}$ & 166 & Mesothelin & $20.0 \mathrm{nmol} / \mathrm{L}$ & 17 & 14 & 7 & 128 & 14 & 11 \\
\hline Fujimoto et $a{ }^{\beta 6}$ & 96 & Mesothelin & $8.0 \mathrm{nmol} / \mathrm{L}$ & 16 & 23 & 7 & 50 & 16 & 9 \\
\hline Yamada et al ${ }^{41}$ & 98 & Mesothelin & $10.0 \mathrm{nmol} / \mathrm{L}$ & 36 & 9 & 9 & 44 & 16 & 9 \\
\hline Ashour et $a l^{42}$ & 74 & Mesothelin & $3.0 \mathrm{nmol} / \mathrm{L}$ & 19 & 9 & 7 & 39 & 13 & 9 \\
\hline Blanquart et $a f^{43}$ & 101 & Mesothelin & $24.05 \mathrm{nmol} / \mathrm{L}$ & 61 & 14 & 0 & 26 & 12 & 9 \\
\hline Amany et $a l^{44}$ & 40 & Mesothelin & $3.5 \mathrm{nmol} / \mathrm{L}$ & 19 & 2 & 1 & 18 & 12 & 9 \\
\hline Canessa et $a{ }^{45}$ & 275 & Mesothelin & $9.3 \mathrm{nmol} / \mathrm{L}$ & 38 & 27 & 14 & 196 & 16 & 10 \\
\hline Creaney et $a^{46}$ & 98 & Mesothelin & $20.0 \mathrm{nmol} / \mathrm{L}$ & 30 & 3 & 13 & 52 & 13 & 11 \\
\hline Creaney et a/ ${ }^{46}$ & 98 & MPF & $600.0 \mathrm{ng} / \mathrm{mL}$ & 35 & 3 & 6 & 52 & 13 & 11 \\
\hline Filiberti et $a f^{48}$ & 177 & Mesothelin & $12.0 \mathrm{nmol} / \mathrm{L}$ & 42 & 17 & 15 & 103 & 14 & 12 \\
\hline Hooper et al ${ }^{49}$ & 193 & Mesothelin & $20.0 \mathrm{nmol} / \mathrm{L}$ & 18 & 21 & 7 & 147 & 15 & 12 \\
\hline
\end{tabular}




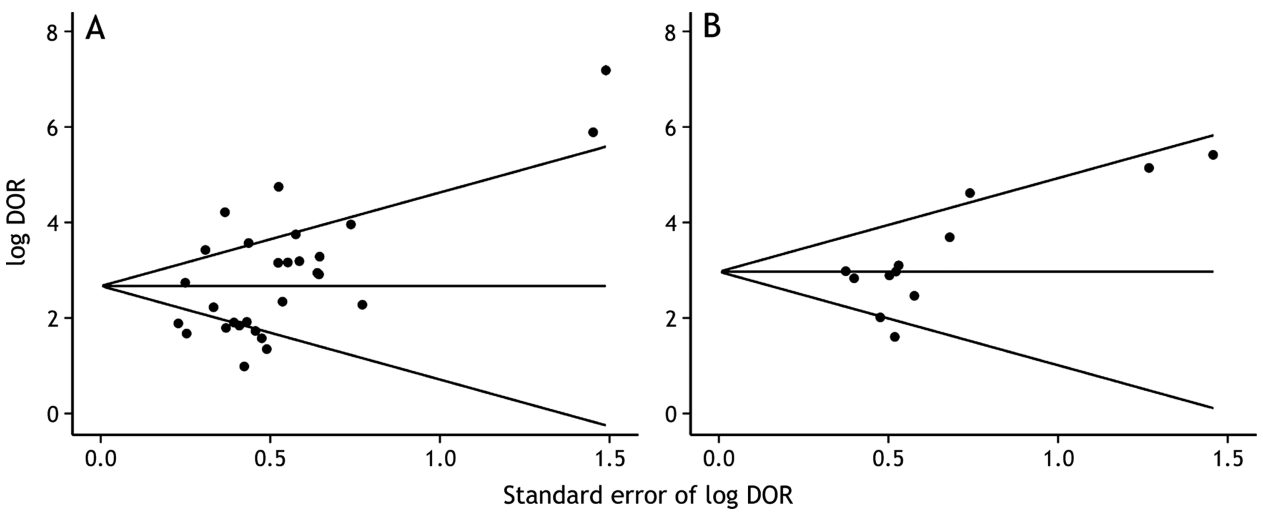

Figure 1 Funnel graphs for the assessment of potential publication bias in soluble mesothelin family proteins in (A) serum and (B) pleural fluid for diagnosing malignant pleural mesothelioma. The funnel graph plots the log of the diagnostic OR (DOR) against the SE of the log of the DOR (an indicator of sample size). Each solid circle represents each study in the meta-analysis. The line in the centre indicates the summary DOR.

\section{Study characteristics}

On review, the studies showed large differences in the number of participants, clinical characteristics (especially histological subtypes of MPM and type of control groups) and reported diagnostic cut-off values of SMRPs (see online supplementary appendix 2). For serum SMRP studies, the average sample size was 265 (range 40-1086) and the subjects included 1562 patients with MPM and 5988 non-MPM. For PF SMRP studies, the average sample size was 126 (range 40-275) and the subjects included 460 patients with MPM and 1046 non-MPM.

In 21 publications the diagnosis of MPM was completely based on pathological findings in pleural biopsies, with or without positive cytological results while, in the remaining nine publications, some patients with MPM were diagnosed based only on the cytological findings. The quality of the study design and reporting of diagnostic accuracy of most studies were generally good since 26 of 30 publications had higher STARD scores $(\geq 13)$ and 21 studies had higher QUADAS scores $(\geq 10)$.

\section{Publication bias}

The funnel plots for publication bias showed asymmetry for serum SMRP studies (figure 1A) and evaluation of publication bias showed that Egger tests were significant for serum SMRPs $(p=0.038)$. The funnel plots for publication bias also showed asymmetry for PF SMRP studies (figure 1B) and Egger tests showed that this was significant for PF SMRPs $(p=0.035)$. These results indicated a potential for publication bias for both serum and $\mathrm{PF}$ SMRP studies.

\section{Diagnostic accuracy}

Figure 2A shows a forest plot of sensitivity and specificity for 28 serum SMRP studies in the diagnosis of MPM. The sensitivity ranged from 0.33 to 0.95 (pooled 0.61 , $95 \%$ CI 0.58 to 0.63 ) while specificity ranged from 0.60 to 1.00 (pooled $0.87,95 \%$ CI 0.86 to 0.88 ). It was also noted that PLR was 5.71 (95\% CI 4.28 to 7.62 ), NLR was $0.43(95 \%$ CI 0.38 to 0.50$)$ and DOR was 14.43 (95\% CI 9.98 to 20.87$). \chi^{2}$ values of sensitivity, specificity, PLR, NLR and DOR were 153.68, 460.32, 272.50, 143.64 and 142.07 , respectively (all $\mathrm{p}<0.001$ ), indicating a significant heterogeneity between studies.

Figure 2B shows a forest plot of sensitivity and specificity for 12 PF SMRP studies in the diagnosis of MPM. The sensitivity ranged from 0.70 to 1.00 (pooled 0.79 , $95 \%$ CI 0.75 to 0.83 ) while specificity ranged from 0.65 to 0.95 (pooled $0.85,95 \%$ CI 0.83 to 0.87 ). We also noted that PLR was 4.78 (95\% CI 3.52 to 6.50 ), NLR was $0.30(95 \%$ CI 0.24 to 0.36$)$ and DOR was $19.50(95 \%$ CI 12.14 to 31.33$) \cdot \chi^{2}$ values of sensitivity, specificity, PLR, NLR and DOR were $41.33(\mathrm{p}<0.001), 46.78(\mathrm{p}<0.001)$, $38.64(\mathrm{p}<0.001), 14.53(\mathrm{p}=0.205)$ and $23.49(\mathrm{p}=0.015)$, respectively, indicating some heterogeneity between studies.

The graphs of SROC curves for SMRP determinations showing sensitivity versus 1 - specificity from individual studies are shown in figure 3. The SROC curve for serum SMRPs was not positioned near the desirable upper left corner of the curve and the maximum joint sensitivity and specificity was 0.741 (SEM 0.029; figure $3 \mathrm{~A}$ ) while the area under the curve (AUC) was 0.806 (SEM 0.032). The maximum joint sensitivity and specificity of PF SMRP was 0.820 (SEM 0.022) while the AUC was 0.890 (SEM 0.021; figure 3B).

Thus, in total, the diagnostic performance of SMRPs in serum and PF was similar.

\section{Subgroup analysis}

We first analysed the diagnostic values of serum mesothelin and MPF separately and the results are presented in table 3. Based on the comparisons of sensitivity, specificity, PLR, NLR, DOR and AUC, the diagnostic performance of serum MPF was superior to that of serum mesothelin. 

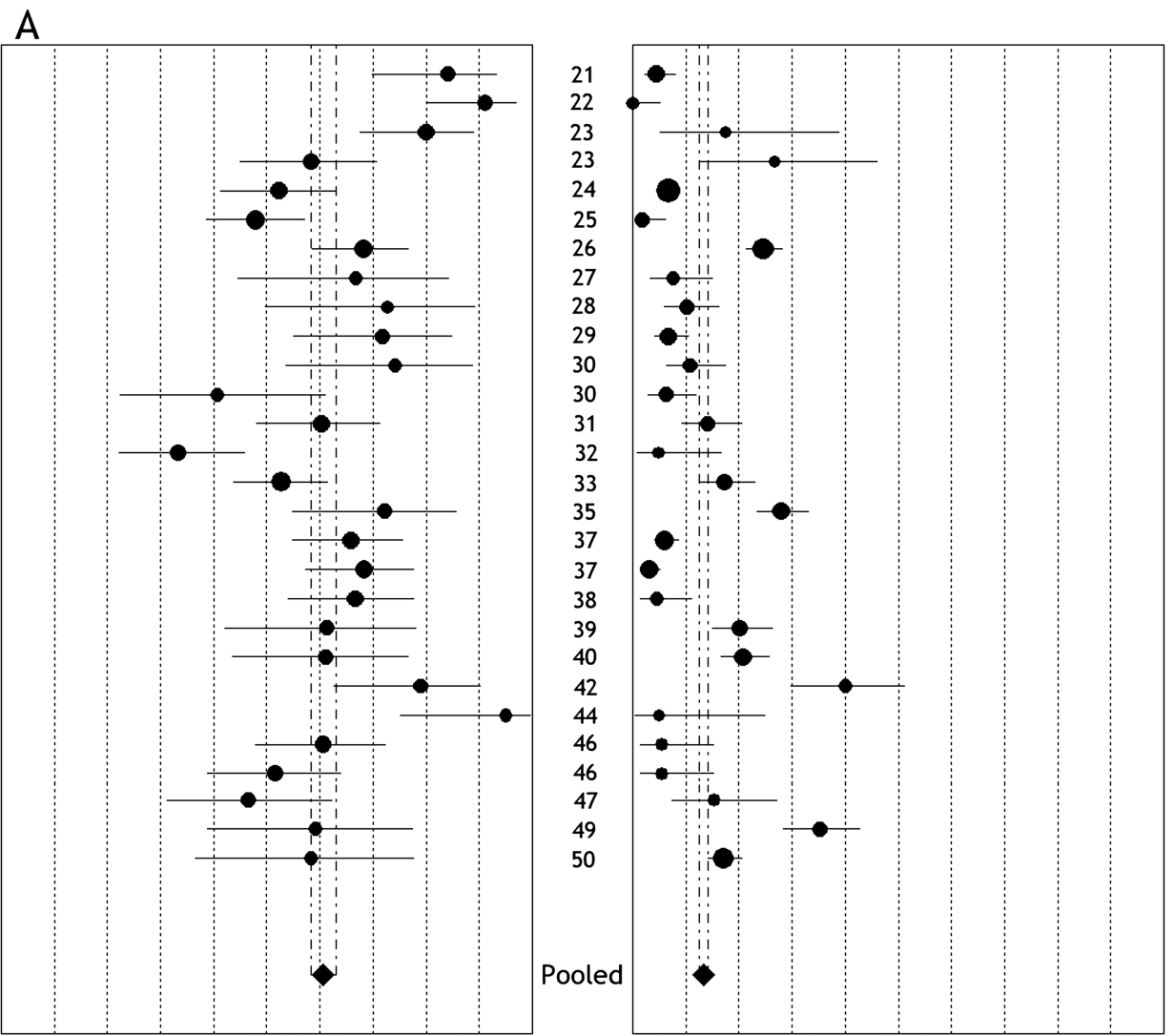

B
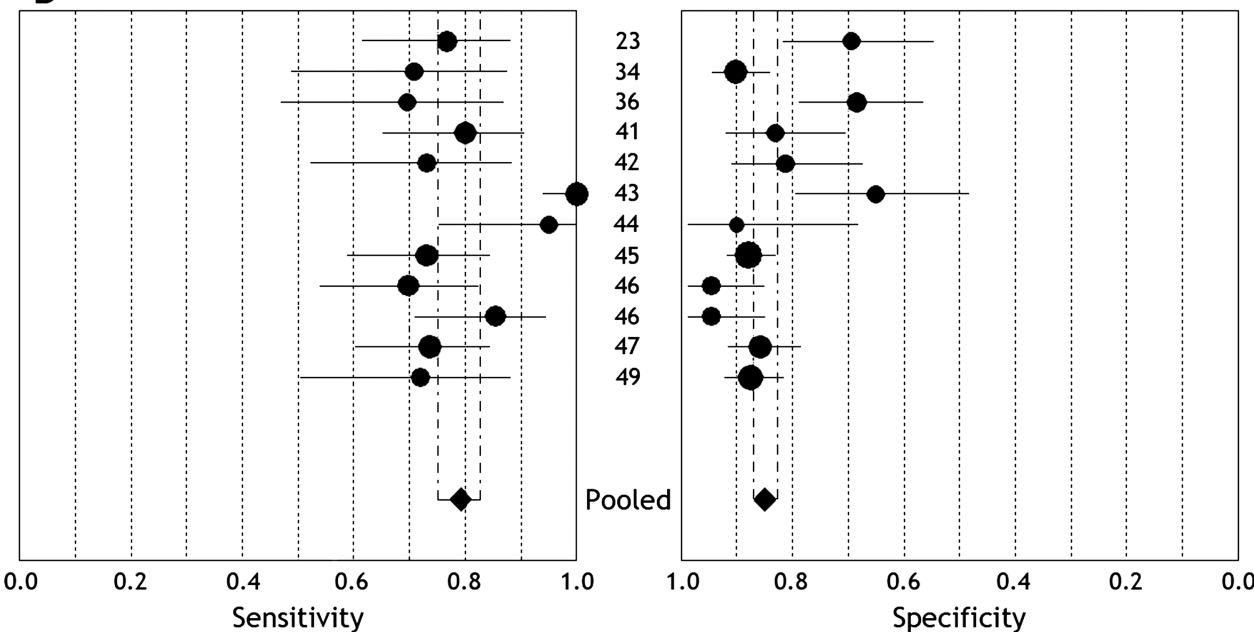

Figure 2 Forest plots of estimates of sensitivity and specificity for soluble mesothelin family proteins in (A) serum and (B) pleural fluid for diagnosing malignant pleural mesothelioma. The point estimates of sensitivity and specificity from each study are shown as solid circles. Error bars are 95\% Cls. Numbers indicate the reference numbers of studies cited in the reference list.

Data from six studies 212224283031 were available for comparing the diagnostic accuracy of serum SMRPs in differentiating MPM from healthy control subjects, nine studies 212324263031334547 were available for differentiating MPM from other malignancies and eight studies $^{21} 23-2528303340$ were available for differentiating MPM from asbestos-exposed subjects. As shown in table 4, the values of sensitivity, specificity, PLR, NLR, DOR and AUC of SMRPs for discriminating between patients with MPM and healthy control subjects were quite acceptable, and were better than those for discriminating between patients with MPM and those with other cancers or asbestos-exposed people. By using serum SMRPs, it was more difficult to differentiate MPM from other cancers than from healthy controls or asbestos-exposed people.

Six studies ${ }^{23} 3436414248$ provided the required data for comparing the diagnostic accuracy of PF mesothelin in differentiating MPM from other cancers and four studies $^{36} 414248$ provided data for differentiating MPM 


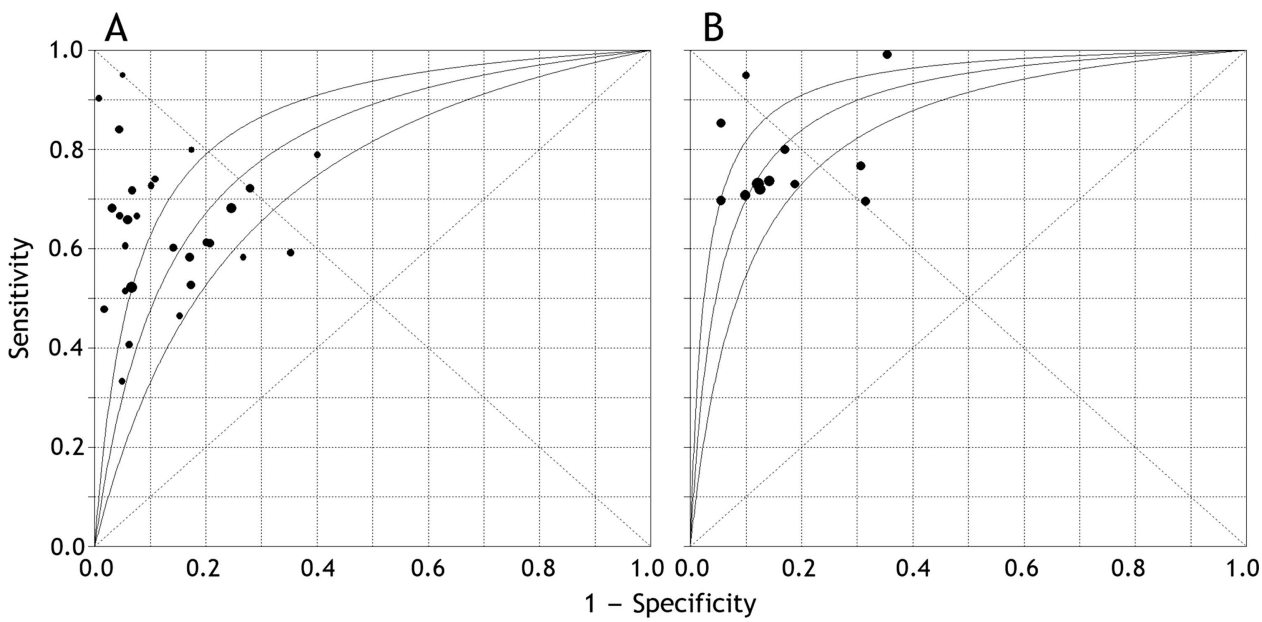

Figure 3 Summary receiver operating characteristic (SROC) curves with $95 \%$ Cls for soluble mesothelin family proteins in (A) serum and (B) pleural fluid for diagnosing malignant pleural mesothelioma. Each solid circle represents each study in the meta-analysis. The size of each study is indicated by the size of the solid circle. The regression SROC curves summarise the overall diagnostic accuracy.

from benign pleural effusions (table 5). In total, the diagnostic accuracy of PF SMRP in differentiating MPM from other cancers was very similar to that of differentiating between MPM and benign pleural effusions.

\section{DISCUSSION}

The diagnosis of MPM is always challenging because (1) MPM may appear in patients up to 30-40 years after exposure to asbestos; (2) the clinical and imaging signs of MPM are non-specific; and (3) a definitive diagnosis, which relies on histology, can sometimes be very difficult to achieve, even with the use of immunohistochemistry. ${ }^{5}$ To date, no single marker or panel of soluble biomarkers is available for a clear diagnosis of MPM..$^{51} 52$

In the present meta-analysis our results indicated that the pooled sensitivity of serum and PF SMRPs was 0.61 and 0.79 , respectively, and their specificity was 0.87 and
0.85 , respectively. These data indicated that the sensitivity and specificity of SMRPs in serum and PF were not as high as expected. SMRPs might be helpful in confirming (ruling in) MPM if the results are higher than the cut-off values. Thus, positive SMRP test results suggested that invasive diagnostic steps such as medical thoracoscopy might be necessary. On the other hand, the low sensitivity will not allow exclusion of non-MM patients even if the patients have mesothelin concentrations lower than the cut-off value. The associated poor sensitivity of SMRPs therefore clearly limits their added value to the diagnosis of MPM.

As previously described, ${ }^{11}$ SROC curves present a global summary of test performance and show the tradeoff between sensitivity and specificity while DOR is a single indicator of test accuracy that combines the data from sensitivity and specificity into a single number. The results of our analyses based on SROC curves showed

\begin{tabular}{lcc}
\multicolumn{2}{c}{ Table 3} & Comparison of diagnostic accuracy of mesothelin and megakaryocyte potentiating factor in serum \\
\hline & Mesothelin & Megakaryocyte potentiating factor \\
\hline Studies (reference numbers) & $21,23-28,30,31,33,35,37-40,42,44,46,47,49,50$ & $22,29,30,32,37,46$ \\
Sensitivity $(95 \% \mathrm{Cl})$ & $0.62(0.59$ to 0.65$)$ & $0.62(0.56$ to 0.67$)$ \\
Heterogeneity $(p$ value) & $70.20(<0.001)$ & $53.08(<0.001)$ \\
Specificity $(95 \% \mathrm{Cl})$ & $0.85(0.84$ to 0.86$)$ & $0.96(0.94$ to 0.97$)$ \\
Heterogeneity $(p$ value) & $352.24(<0.001)$ & $17.60(0.001)$ \\
PLR $(95 \% \mathrm{Cl})$ & $4.78(3.59$ to 6.36$)$ & $12.39(5.53$ to 27.74$)$ \\
Heterogeneity $(p$ value) & $185.80(<0.001)$ & $14.42(0.006)$ \\
NLR $(95 \% \mathrm{Cl})$ & $0.45(0.40$ to 0.51$)$ & $0.34(0.19$ to 0.63$)$ \\
Heterogeneity $(p$ value) & $50.65(<0.001)$ & $67.07(<0.001)$ \\
DOR $(95 \% \mathrm{Cl})$ & $11.84(8.12$ to 17.27$)$ & $36.08(12.91$ to 100.85$)$ \\
Heterogeneity $(p$ value) & $95.80(<0.001)$ & $13.40(0.009)$ \\
AUC (SEM) & $0.785(0.033)$ & $0.941(0.094)$
\end{tabular}

${ }^{*} \mathrm{Q}$ value.

AUC, area under curve; DOR, diagnostic OR; NLR, negative likelihood ratio; PLR, positive likelihood ratio. 
Table 4 Comparisons of diagnostic accuracy of SMRPs in serum for differentiating MPM from different control subpopulations

\begin{tabular}{lccc}
\hline & $\begin{array}{l}\text { MPM vs healthy } \\
\text { controls }\end{array}$ & MPM vs other cancers & $\begin{array}{c}\text { MPM vs benign } \\
\text { asbestos-related diseases }\end{array}$ \\
\hline Studies (reference numbers) & $21,22,24,28,30,31$ & $21,23,24,26,30,31,33,45,47$ & $21,23,24,25,28,30,33,40$ \\
Sensitivity $(95 \% \mathrm{Cl})$ & $0.66(0.61$ to 0.71$)$ & $0.60(0.56$ to 0.64$)$ & $0.58(0.54$ to 0.62$)$ \\
Heterogeneity $(\mathrm{p}$ value) & $42.46(<0.001)$ & $31.33(<0.001)$ & $39.91(<0.001)$ \\
Specificity $(95 \% \mathrm{Cl})$ & $0.97(0.96$ to 0.98$)$ & $0.81(0.78$ to 0.83$)$ & $0.89(0.86$ to 0.91$)$ \\
Heterogeneity $(p$ value) & $46.70(<0.001)$ & $52.59(<0.001)$ & $39.48(<0.001)$ \\
PLR $(95 \% \mathrm{Cl})$ & $24.07(4.03$ to 143.68$)$ & $2.81(2.11$ to 3.73$)$ & $6.65(3.69$ to 12.00$)$ \\
Heterogeneity $(p$ value) & $48.35(<0.001)$ & $26.73(0.001)$ & $25.91(0.001)$ \\
NLR $(95 \% \mathrm{Cl})$ & $0.33(0.22$ to 0.50$)$ & $0.52(0.43$ to 0.63$)$ & $0.44(0.36$ to 0.55$)$ \\
Heterogeneity $(p$ value) & $32.11(<0.001)$ & $25.45(0.001)$ & $24.89(0.001)$ \\
DOR (95\% Cl) & $69.27(15.67$ to 306.21) & $5.62(3.67$ to 8.59$)$ & $18.03(8.90$ to 36.52$)$ \\
Heterogeneity $(p)$ & $20.80(0.001)$ & $22.70(0.004)$ & $19.16(0.008)$ \\
AUC (SEM) & $0.870(0.120)$ & $0.734(0.055)$ & $0.845(0.057)$
\end{tabular}

${ }^{*} \mathrm{Q}$ value.

AUC, area under curve; DOR, diagnostic OR; MPM, malignant pleural mesothelioma; NLR, negative likelihood ratio; PLR, positive likelihood ratio; SMRP, soluble mesothelin-related peptide.

that the maximum joint sensitivity and specificity of serum and PF SMRPs were 0.741 and 0.820 , respectively, while their AUCs were 0.806 and 0.890 , respectively, indicating that the level of overall accuracy was not as high as expected. We also found that the pooled DORs of serum and PF SMRPs were 14.43, and 19.50, respectively, indicating that SMRPs seemed to be helpful in the diagnosis of MPM but they were not perfect.

Since SROC curves and DOR are not easy to interpret and use in clinical practice, and since PLR and NLR are considered more clinically meaningful, ${ }^{53} 54$ we further presented both PLR and NLR as our measures of diagnostic accuracy. If a value is $>10$ or $<0.1$, PLR or NLR generates large and often conclusive shifts from pre-test to post-test probability (indicating high accuracy). ${ }^{55}$ A PLR value of 5.71 with serum SMRPs suggests that patients with MPM have a nearly sixfold higher chance of being SMRP-positive compared with patients without MPM, and this was not high enough for the clinical purpose. On the other hand, the NLR value of serum SMRPs was found to be 0.43. If serum SMRP results were negative, the probability that the patient has MPM is $43 \%$, which is not low enough to rule out MPM. Very similar results were found with PF SMRPs.

Although both mesothelin and MPF belong to mesothelin family proteins, we noted in the current meta-analysis that the overall diagnostic measures including sensitivity, specificity, PLR, NLR, DOR and AUC of serum MPF were better than those of serum mesothelin. MPF therefore had a superior diagnostic accuracy than mesothelin for MPM. We also noted that the diagnostic performance of serum SMRP for discriminating MPM from healthy control subjects was the best (although not as good as expected), followed by that for discriminating

Table 5 Comparisons of diagnostic accuracy of mesothelin in pleural fluid for differentiation of MPM from different control subpopulations

\begin{tabular}{|c|c|c|}
\hline & MPM vs other cancers & MPM vs benign diseases \\
\hline Studies (reference numbers) & $23,34,36,41,42,48$ & $36,41,42,48$ \\
\hline Sensitivity $(95 \% \mathrm{Cl})$ & 0.75 (0.69 to 0.80$)$ & $0.75(0.67$ to 0.82$)$ \\
\hline Heterogeneity* ( $p$ value) & $1.36(0.929)$ & $1.08(0.783)$ \\
\hline Specificity $(95 \% \mathrm{Cl})$ & $0.76(0.71$ to 0.82$)$ & $0.87(0.80$ to 0.93$)$ \\
\hline Heterogeneity ( $p$ value) & $4.88(0.430)$ & $6.74(0.081)$ \\
\hline $\operatorname{PLR}(95 \% \mathrm{Cl})$ & 2.95 (2.32 to 3.75$)$ & 4.74 (2.30 to 9.76$)$ \\
\hline Heterogeneity ( $p$ value) & $4.83(0.437)$ & $7.01(0.071)$ \\
\hline $\operatorname{NLR}(95 \% \mathrm{Cl})$ & $0.34(0.27$ to 0.43$)$ & $0.30(0.22$ to 0.40$)$ \\
\hline Heterogeneity ( $p$ value) & $1.94(0.857)$ & $1.83(0.608)$ \\
\hline DOR $(95 \% \mathrm{Cl})$ & 8.96 (5.78 to 13.89$)$ & 16.87 (6.79 to 41.92$)$ \\
\hline Heterogeneity ( $p$ value) & $3.34(0.648)$ & $5.26(0.154)$ \\
\hline AUC (SEM) & $0.809(0.025)$ & $0.818(0.050)$ \\
\hline
\end{tabular}

${ }^{*} \mathrm{Q}$ value.

AUC, area under curve; DOR, diagnostic OR; MPM, malignant pleural mesothelioma; NLR, negative likelihood ratio; PLR, positive likelihood ratio. 
MPM from patients with other cancers or from asbestos-exposed people. In addition, the overall diagnostic accuracy of PF SMRP for differentiating MPM from other cancers was similar to that of differentiating MPM from benign pleural effusions.

Our meta-analysis had several limitations. First, exclusion of conference abstracts, letters to the editors and non-English language studies may have led to publication bias. Indeed, we observed a publication bias for both serum and PF SMRP studies. Publication bias may also be introduced by inflation of diagnostic accuracy estimates since studies that report positive results are more likely to be accepted for publication. Second, pathological types of MPM were not specified in three studies, ${ }^{35} 4250$ and the epithelioid subtype of MPM was the most common pathological type in all studies, excluding the one reported by Creaney et $a .^{25}$ In total, $69.9 \%(982 / 1404)$ of MPM were epithelioid subtype (range 29.9-100\%). Analysis in terms of histological type has shown that SMRP levels are significantly higher in epithelioid subtype MPM than in other types. ${ }^{21} 2329$ This could partly explain the rather low sensitivity of SMRPs in MPM diagnosis. Third, control populations were very heterogeneous from one study to another and various cut-off points were used for distinguishing between MPM and controls, other cancers or benign respiratory diseases, according to the best combination of sensitivity and specificity. These issues regarding accuracy of diagnosis could also lead to biased results.

It should be mentioned that, since our previous meta-analysis was published, ${ }^{11}$ the use of SMRPs in clinical practice has moved forward significantly. ${ }^{10}$ It has been recognised that SMRPs are diagnostic markers and also serve as markers of the disease course and response to treatment. ${ }^{5657}$ The application of SMRPs in clinical practice in the near future may therefore be in monitoring the response to treatment rather than in guiding diagnostic decisions and risk assessment of asbestos-exposed populations.

In conclusion, the current evidence supports the view that SMRPs in both serum and PF are helpful markers for diagnosing MPM. The overall diagnostic performance of SMRPs in serum and PF was similar, and serum MPF had superior diagnostic accuracy compared with serum mesothelin. The negative results of SMRP determinations were not sufficient to exclude non-MPM whereas the positive test results might be helpful in confirming MPM.

Contributors H-ZS was responsible for the study conception and protocol design and wrote the first draft of the paper. $A C$ and $X$-GJ were responsible for the overall study coordination under the supervision of $\mathrm{H}-\mathrm{ZS}$ with contributions from KZ and Z-HT. All literature searching, abstract screening, study selection and data extraction was undertaken independently by $A C$ and $\mathrm{X}$-GJ with referral to $\mathrm{KZ}$ as a third reviewer as necessary. Assessment of methodological quality was also undertaken by Z-HT and H-ZS. All authors have read and approved the final version of the manuscript.

Funding This work was supported in part by a grant from the National Natural Science Foundation of China (№. 81270149) and in part by a grant from the 12th Five-Year National Science and Technology Program of Social Development, Ministry of Science and Technology, China (No. 2012BAI05B02).
Competing interests None.

Provenance and peer review Not commissioned; externally peer reviewed.

Data sharing statement No additional data are available.

Open Access This is an Open Access article distributed in accordance with the Creative Commons Attribution Non Commercial (CC BY-NC 3.0) license, which permits others to distribute, remix, adapt, build upon this work noncommercially, and license their derivative works on different terms, provided the original work is properly cited and the use is non-commercial. See: http:// creativecommons.org/licenses/by-nc/3.0/

\section{REFERENCES}

1. Robinson BW, Musk AW, Lake RA. Malignant mesothelioma. Lancet 2005;366:397-408

2. West SD, Lee YC. Management of malignant pleural mesothelioma. Clin Chest Med 2006;27:335-54.

3. Vogelzang NJ, Rusthoven JJ, Symanowski J, et al. Phase III study of pemetrexed in combination with cisplatin versus cisplatin alone in patients with malignant pleural mesothelioma. J Clin Oncol 2003;21:2636-44

4. van Meerbeeck JP, Gaafar R, Manegold C, et al. Randomized phase III study of cisplatin with or without raltitrexed in patients with malignant pleural mesothelioma: an intergroup study of the European Organisation for Research and Treatment of Cancer Lung Cancer Group and the National Cancer Institute of Canada. J Clin Oncol 2005;23:6881-9.

5. Scherpereel A, Astoul P, Baas P, et al. Guidelines of the European Respiratory Society and the European Society of Thoracic Surgeons for the management of malignant pleural mesothelioma. Eur Respir $J$ 2010;35:479-95.

6. van der Bij S, Schaake E, Koffijberg $\mathrm{H}$, et al. Markers for the non-invasive diagnosis of mesothelioma: a systematic review. $\mathrm{Br} \mathrm{J}$ Cancer 2011;104:1325-33.

7. Chang K, Pastan I. Molecular cloning of mesothelin, a differentiation antigen present on mesothelium, mesotheliomas, and ovarian cancers. Proc Natl Acad Sci USA 1996;93:136-40.

8. Sapede C, Gauvrit A, Barbieux I, et al. Aberrant splicing and protease involvement in mesothelin release from epithelioid mesothelioma cells. Cancer Sci 2008;99:590-4.

9. Maeda M, Hino O. Molecular tumor markers for asbestos-related mesothelioma: serum diagnostic markers. Pathol Int 2006;56:649-54.

10. Pantazopoulos I, Boura P, Xanthos T, et al. Effectiveness of mesothelin family proteins and osteopontin for malignant mesothelioma. Eur Respir J 2013:41:706-15.

11. Luo L, Shi HZ, Liang QL, et al. Diagnostic value of soluble mesothelin-related peptides for malignant mesothelioma: a meta-analysis. Respir Med 2010;104:149-56.

12. Hollevoet K, Reitsma JB, Creaney J, et al. Serum mesothelin for diagnosing malignant pleural mesothelioma: an individual patient data meta-analysis. J Clin Oncol 2012;30:1541-9.

13. Bossuyt PM, Reitsma JB, Bruns DE, et al. Towards complete and accurate reporting of studies of diagnostic accuracy: the STARD initiative. BMJ 2003;326:41-4.

14. Whiting P, Rutjes AW, Reitsma JB, et al. The development of QUADAS: a tool for the quality assessment of studies of diagnostic accuracy included in systematic reviews. BMC Med Res Methodol 2003;3:25

15. Deville WL, Buntinx F, Bouter LM, et al. Conducting systematic reviews of diagnostic studies: didactic guidelines. BMC Med Res Methodol 2002;2:9.

16. Moses LE, Shapiro D, Littenberg B. Combining independent studies of a diagnostic test into a summary ROC curve: data-analytic approaches and some additional considerations. Stat Med 1993;12:1293-316.

17. Liang QL, Shi HZ, Qin XJ, et al. Diagnostic accuracy of tumour markers for malignant pleural effusion: a meta-analysis. Thorax 2008;63:35-41.

18. Irwig $L$, Macaskill $P$, Glasziou $P$, et al. Meta-analytic methods for diagnostic test accuracy. J Clin Epidemiol 1995;48:119-30.

19. Vamvakas EC. Meta-analyses of studies of the diagnostic accuracy of laboratory tests: a review of the concepts and methods. Arch Pathol Lab Med 1998:122:675-86.

20. Egger M, Davey Smith G, Schneider M, et al. Bias in meta-analysis detected by a simple, graphical test. BMJ 1997;315:629-34.

21. Robinson BW, Creaney J, Lake R, et al. Mesothelin-family proteins and diagnosis of mesothelioma. Lancet 2003;362:1612-16. 
22. Onda M, Nagata S, Ho M, et al. Megakaryocyte potentiation factor cleaved from mesothelin precursor is a useful tumor marker in the serum of patients with mesothelioma. Clin Cancer Res 2006;12:4225-31.

23. Scherpereel A, Grigoriu B, Conti M, et al. Soluble mesothelin-related peptides in the diagnosis of malignant pleural mesothelioma. Am Respir Crit Care Med 2006;173:1155-60.

24. Beyer HL, Geschwindt RD, Glover CL, et al. MESOMARK: a potentia test for malignant pleural mesothelioma. Clin Chem 2007:53:666-72.

25. Creaney J, van Bruggen I, Hof M, et al. Combined CA125 and mesothelin levels for the diagnosis of malignant mesothelioma. Chest 2007;132:1239-46.

26. Cristaudo A, Foddis R, Vivaldi A, et al. Clinical significance of serum mesothelin in patients with mesothelioma and lung cancer. Clin Cancer Res 2007;13:5076-81.

27. Di Serio F, Fontana A, Loizzi M, et al. Mesothelin family proteins and diagnosis of mesothelioma: analytical evaluation of an automated immunoassay and preliminary clinical results. Clin Chem Lab Med 2007;45:634-8.

28. Amati M, Tomasetti M, Scartozzi M, et al. Profiling tumor-associated markers for early detection of malignant mesothelioma: an epidemiologic study. Cancer Epidemiol Biomarkers Prev 2008;17:163-70.

29. Shiomi K, Hagiwara Y, Sonoue K, et al. Sensitive and specific new enzyme-linked immunosorbent assay for $\mathrm{N}-\mathrm{ERC} / \mathrm{mes}$ thelin increases its potential as a useful serum tumor marker for mesothelioma. Clin Cancer Res 2008;14:1431-7.

30. Iwahori K, Osaki T, Serada S, et al. Megakaryocyte potentiating factor as a tumor marker of malignant pleural mesothelioma: evaluation in comparison with mesothelin. Lung Cancer 2008;62:45-54.

31. van den Heuvel MM, Korse CM, Bonfrer JM, et al. Non-invasive diagnosis of pleural malignancies: the role of tumour markers. Lung Cancer 2008;59:350-4.

32. Creaney J, Yeoman D, Demelker Y, et al. Comparison of osteopontin, megakaryocyte potentiating factor, and mesothelin proteins as markers in the serum of patients with malignant mesothelioma. J Thorac Oncol 2008;3:851-7.

33. Schneider J, Hoffmann H, Dienemann H, et al. Diagnostic and prognostic value of soluble mesothelin-related proteins in patients with malignant pleural mesothelioma in comparison with benign asbestosis and lung cancer. $J$ Thorac Oncol 2008;

3:1317-24

34. Davies HE, Sadler RS, Bielsa S, et al. Clinical impact and reliability of pleural fluid mesothelin in undiagnosed pleural effusions. $A m \mathrm{~J}$ Respir Crit Care Med 2009;180:437-44.

35. Rodriguez Portal JA, Rodriguez Becerra E, Rodriguez Rodriguez D, et al. Serum levels of soluble mesothelin-related peptides in malignant and nonmalignant asbestos-related pleural disease: relation with past asbestos exposure. Cancer Epidemiol Biomarkers Prev 2009;18:646-50.

36. Fujimoto N, Gemba K, Asano M, et al. Soluble mesothelin-related protein in pleural effusion from patients with malignant pleural mesothelioma. Exp Ther Med 2010;1:313-17.

37. Hollevoet K, Nackaerts K, Thimpont J, et al. Diagnostic performance of soluble mesothelin and megakaryocyte potentiating factor in mesothelioma. Am J Respir Crit Care Med 2010;181:620-5.

38. Creaney J, Yeoman D, Musk AW, et al. Plasma versus serum levels of osteopontin and mesothelin in patients with malignant mesothelioma-which is best? Lung Cancer 2011;74:55-60.

39. Cristaudo A, Bonotti A, Simonini S, et al. Combined serum mesothelin and plasma osteopontin measurements in malignant pleural mesothelioma. J Thorac Oncol 2011;6:1587-93.
40. Dipalma N, Luisi V, Di Serio F, et al. Biomarkers in malignant mesothelioma: diagnostic and prognostic role of soluble mesothelin-related peptide. Int J Biol Markers 2011;26:160-5.

41. Yamada S, Tabata C, Tabata R, et al. Clinical significance of pleural effusion mesothelin in malignant pleural mesothelioma. Clin Chem Lab Med 2011;49:1721-6.

42. Ashour WM, Amin H, Sabri IM, et al. Combined blood and pleural levels of mesothelin and osteopontin for the diagnosis of malignant pleural mesothelioma. Egyptian J Chest Dis Tuberc 2012;61: 121-8.

43. Blanquart C, Gueugnon F, Nguyen JM, et al. CCL2, galectin-3, and SMRP combination improves the diagnosis of mesothelioma in pleural effusions. J Thorac Oncol 2012;7:883-9.

44. Amany FM, Mohamed NA, El-Ghamry R, et al. Mesothelin and osteopontin as diagnostic and prognostic markers of malignant pleural mesothelioma in Egyptian patients undergoing pleurodesis. Egyptian J Chest Dis Tuberc 2013;62:115-20.

45. Canessa PA, Franceschini MC, Ferro P, et al. Evaluation of soluble mesothelin-related peptide as a diagnostic marker of malignant pleural mesothelioma effusions: its contribution to cytology. Cancer Invest 2013;31:43-50.

46. Creaney J, Sneddon S, Dick IM, et al. Comparison of the diagnostic accuracy of the MSLN gene products, mesothelin and megakaryocyte potentiating factor, as biomarkers for mesothelioma in pleural effusions and serum. Dis Markers 2013;35:119-27.

47. Ferro P, Canessa PA, Battolla E, et al. Mesothelin is more useful in pleural effusion than in serum in the diagnosis of pleural mesothelioma. Anticancer Res 2013;33:2707-13.

48. Filiberti R, Parodi S, Libener R, et al. Diagnostic value of mesothelin in pleural fluids: comparison with CYFRA 21-1 and CEA. Med Oncol 2013;30:543.

49. Hooper CE, Morley AJ, Virgo P, et al. A prospective trial evaluating the role of mesothelin in undiagnosed pleural effusions. Eur Respir $J$ 2013;41:18-24

50. Bayram M, Dongel I, Akbaş A, et al. Serum biomarkers in patients with mesothelioma and pleural plaques and healthy subjects exposed to naturally occurring asbestos. Lung. Published Online First: 30 Oct 2013. doi: 10.1007/s00408-013-9526-9

51. Husain AN, Colby TV, Ordonez NG, et al. Guidelines for pathologic diagnosis of malignant mesothelioma: a consensus statement from the International Mesothelioma Interest Group. Arch Pathol Lab Med 2009;133:1317-31.

52. Cristaudo A, Bonotti A, Simonini S, et al. Soluble markers for diagnosis of malignant pleural mesothelioma. Biomark Med 2011;5:261-73.

53. Deeks J. Systematic reviews of evaluations of diagnostic and screening tests. In: Egger M, Smith GD, Altman DG, eds. Systematic reviews in health care. Meta-analysis in context. London: BMJ Publishing Group, 2001:248-82.

54. Jaeschke R, Guyatt G, Lijmer J. Diagnostic tests. In: Guyatt G, Rennie D, eds. Users' guides to the medical literature. A manual for evidence-based clinical practice. Chicago, IL: AMA Press, 2002;121-40.

55. Pass HI, Wali A, Tang N, et al. Soluble mesothelin-related peptide level elevation in mesothelioma serum and pleural effusions. Ann Thorac Surg 2008;85:265-72.

56. Grigoriu BD, Chahine B, Vachani A, et al. Kinetics of soluble mesothelin in patients with malignant pleural mesothelioma during treatment. Am J Respir Crit Care Med 2009;179:950-4.

57. Wheatley-Price P, Yang B, Patsios D, et al. Soluble mesothelin-related peptide and osteopontin as markers of response to treatment in malignant mesothelioma. J Clin Oncol 2010;28:3316-22. 